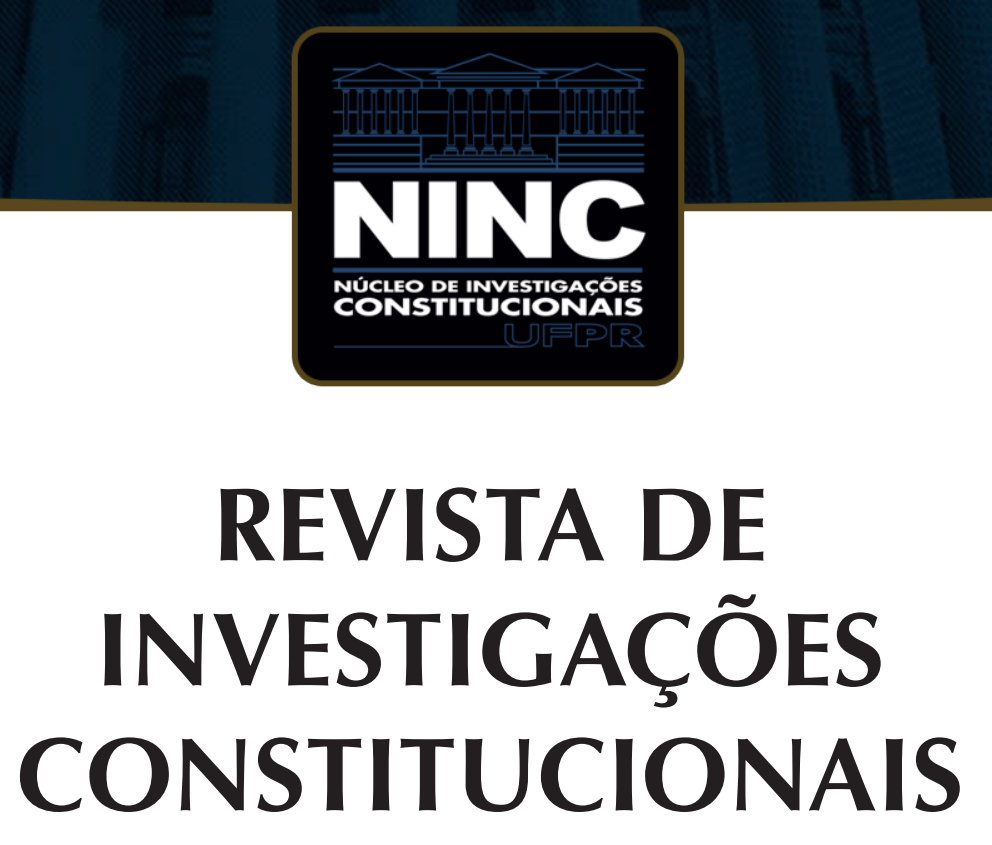

JOURNAL OF CONSTITUTIONAL RESEARCH

vol. 8 | n. 3 | setembro/dezembro 2021 | ISSN 2359-5639 | Periodicidade quadrimestral Curitiba | Núcleo de Investigações Constitucionais da UFPR | www.ninc.com.br 


\title{
A relevância do direito à seguridade social na manutenção do regime democrático
}

\section{The relevance of the right to social security in maintenance of the democratic regime}

\author{
DENISE BZYL FEITOSA ${ }^{1, *}$ \\ ' Universidade de Fortaleza (Fortaleza, Ceará, Brasil) \\ denisebzyl@hotmail.com \\ https://orcid.org/0000-0001-7441-8942
}

\section{MARIA LÍRIDA CALOU DE ARAÚJO 1, **}

' Universidade de Fortaleza (Fortaleza, Ceará, Brasil)

liridacalou@unifor.br

https://orcid.org/0000-0001-5710-7499

Recebido/Received: $16.07 .2020 /$ July $16^{\text {th }}, 2020$ Aprovado/Approved: 02.04.2021 / April 2 ${ }^{\text {nd }}, 2021$

\section{Resumo}

A proteção social, importante instrumento para elevar a qualidade de vida das pessoas, é base de uma sociedade democraticamente forte. A garantia de realização de direitos sociais reverbera na qualidade da participação popular nos processos políticos, pois as pessoas deixam de

\section{Abstract}

Social protection, an important tool for raising people's quality of life, is the basis of a democratically strong society. The guarantee of realization of social rights reverberates in the quality of popular participation in political processes, as people stop worrying only about issues of mere

Como citar esse artigo/How to cite this article: FEITOSA, Denise Bzyl; ARAÚJO, Maria Lírida Calou de. A relevância do direito à seguridade social na manutenção do regime democrático. Revista de Investigações Constitucionais, Curitiba, vol. 8, n. 3, p. 837-856, set./dez. 2021. DOI: 10.5380/rinc.v8i3.75263.

" Mestra pelo Programa de Pós-Graduação em Direito Constitucional Público e Teoria Política da Universidade de Fortaleza (Fortaleza-CE, Brasil). Integrante do Grupo de Pesquisa Administração Pública e Tributação no Brasil (GEPDAT). Especialista em Direito Tributário pelo Centro Universitário Estácio do Ceará (2018). Bacharela em Direito pela Universidade de Fortaleza (2006). Advogada (OAB/CE n 18.588). E-mail: denisebzyl@hotmail.com.

** Professora titular do Programa de Pós-graduação em Direito Constitucional - Mestrado e Doutorado - e professora do curso de graduação em Direito da Universidade de Fortaleza (Fortaleza-CE, Brasil). Pós-doutora em Direito Tributário pela Universidade Federal de Santa Catarina (UFSC). Doutora em Direito Público pela Universidade Federal de Pernambuco (UFPE). Mestre em Ordem Jurídica Constitucional pela Universidade Federal do Ceará (UFC). Foi coordenadora e professora titular do curso de graduação em Direito do Centro Universitário Católica de Quixadá (UNICATÓLICA), e é professora aposentada da Universidade Estadual do Ceará (UECE). Coordenadora-geral do Grupo de Estudos e Pesquisas em Direito Administrativo e Tributário (GEPDAT). E-mail: liridacalou@unifor.br. 
se preocupar apenas com questões de mera sobrevivência e passam atuar efetivamente na tomada de decisões da sociedade. Embora a seguridade social demonstre relevância na ordem jurídica, o seu orçamento sofre ingerências que afetam a solvabilidade e robustez do sistema. Objetiva-se estudar a importância desse direito na formação de atores políticos de qualidade. A relevância está nas constantes propostas de maior austeridade no regramento de concessão de benefícios previdenciários e no neoliberalismo que pretende diminuir o tamanho do Estado, o que pode gerar menor cobertura social e diminuição dos índices de qualidade de vida da população, afetando de sobremaneira a participação popular na política. Numa pesquisa doutrinária, foram analisados pensamentos dos juristas a respeito dessa relação entre direitos de seguridade e democracia e se o tratamento desfavorecido conferido a esses direitos reflete na arrecadação. Conclui-se pelo desvirtuamento do tratamento do direito à seguridade social na ordem jurídica, com consequente reflexo nas ingerências sofridas pelo seu orçamento, enfraquecendo a democracia.

Palavras-chave: seguridade social; direitos fundamentais; tributação; contribuições sociais; democracia. survival and start to act effectively in the decision-making of society. Although social security shows relevance in the legal order, its budget suffers interference that affects the solvency and robustness of the system. The objective is to study the importance of this right in the formation of quality political actors. The relevance is in the constant proposals for greater austerity in the rules for granting social security benefits and in neoliberalism that aims to reduce the size of the State, which can generate less social coverage and decrease the quality of life indices of the population, greatly affecting popular participation in politics. In a doctrinal research, the jurists' thoughts about this relationship between security rights and democracy were analyzed and if the disadvantaged treatment given to these rights reflects in the tax collection. It concludes by distorting the treatment of the right to social security in the legal order, with a consequent reflection on the interferences suffered by its budget, weakening democracy.

Keywords: social security; fundamental rights; taxation; social contributions; democracy.

\section{SUMÁRIO}

1. Introdução; 2. A proteção social no Estado Democrático de Direito; 3. O desmonte da Seguridade Social; 4. A fragilização da democracia pela via social; $\mathbf{5}$. Considerações finais; $\mathbf{6}$. Referências.

\section{INTRODUÇÃO}

A proteção em face das contingências sociais é inerente ao ser humano, na medida em que aqueles que se encontram acometidos por doenças, incapacidades, veIhice etc. se apresentam como uma parte vulnerável dentro da sociedade. A garantia de proteção contra essas vicissitudes da vida se dá por meio de um dos direitos sociais conquistados ao longo da história: o direito à seguridade social. Um direito que ganhou status constitucional fundamental, quando da promulgação da Constituição Federal de 1988, mas que sofre constantes ameaças por representar suposto déficit nas contas públicas.

O modelo de Welfare State estabelecido pelo constituinte de 1988 visava uma melhoria na qualidade de vida do povo com a execução de políticas públicas de proteção social. Garantidos os direitos sociais mais básicos pelo Estado, os cidadãos adquiririam maiores poderes de ampliação de suas liberdades individuais até alcançar o pleno exercício dos direitos políticos no Brasil, com uma consciência democrática de qualidade. Esse intuito esbarra no ideal neoliberal que ronda o país, numa tentativa 
de diminuir o tamanho do Estado brasileiro, supostamente ineficiente, a começar pelo desmonte da proteção social, representada pelos institutos de Seguridade Social.

Em que medida o desmonte da proteção social fornecida pelo Estado afeta a democracia? Para esse questionamento surge a hipótese de que talvez a sua importância esteja sendo desvirtuada dentro de um contexto orçamentário que conta com ingerências e malversação do dinheiro público, a fim de se alcançar uma diminuição de um Estado prestacional, que não se atenha tanto à redução da desigualdade social e econômica, tendo em vista que uma sociedade desigual demanda um sistema não participativo para manter-se coesa.

Assim, o presente estudo objetiva, principalmente, descobrir se há esse desmonte da Seguridade Social afetando o Estado Democrático de Direito, mas, também, averiguar como se dá a proteção social sob o enfoque da sociedade e do Estado, bem como analisar o desmonte do Estado Social, por meio das distorções na arrecadação do orçamento securitário. A necessidade premente de estudo do tema está nas constantes tentativas de reformulações das regras de concessão dos benefícios previdenciários, sob alegação de déficit orçamentário. O presente trabalho faz, portanto, uma pesquisa doutrinária, para saber o que os estudiosos da área pensam a respeito do tema.

\section{A PROTEÇÃO SOCIAL NO ESTADO DEMOCRÁTICO DE DIREITO}

A proteção social teve início na família de modo instintivo e, nesses tempos mais remotos em que a noção de Estado ainda não tinha se formado, era o conglomerado familiar que tomava conta dos mais velhos e dos inabilitados para o trabalho. Com o progresso da sociedade, advieram leis e costumes de assistência aos desamparados, mas até a chegada da revolução industrial essa proteção era vista como um dever familiar ou como caridade. ${ }^{1}$

Foi por conta da revolução industrial, que trouxe uma nova leva de trabalhadores vindos do campo para as áreas urbanas, aumentando a oferta de trabalho, com parcos direitos trabalhistas, que foi formulado o conceito de segurança social (pública). O impacto da necessidade de amparo de um número cada vez maior de novos vulneráveis se deveu ao aumento na quantidade de acidentes de trabalho, de doenças relacionadas ao serviço e até mesmo de invalidezes permanentes, fazendo com que o mero cuidado familiar se tornasse insuficiente. Apenas depois da industrialização, a proteção passou a ser vista como uma prestação positiva devida por parte do Estado aos seus cidadãos, quando Otto Von Bismarck criou os seguros sociais, como forma de evitar revoltas populares decorrentes dessa situação insustentável de desamparo dos trabalhadores. ${ }^{2}$

IBRAHIM, Fábio Zambitte. Curso de Direito Previdenciário, 16. ed. Niterói: Impetus, 2011, p.1-3.

2 TSUTIYA, Augusto Massayuki. Curso de Direito da Seguridade Social. 4. ed. São Paulo: Saraiva, 2013, p. 33. 
A consolidação dos direitos sociais (onde se encontram inseridos os direitos de seguridade social), entretanto, só foi se dar no período do pós-guerra, momento em que eles surgiram como uma tentativa de resolver a crise de desigualdade social instaurada no mundo em função do modelo liberal de Estado e dos conflitos armados. Como típica emanação do modelo do Welfare State, os direitos em comento destinavam-se a amparar as pessoas nas suas necessidades espirituais e materiais mais prementes, com o objetivo de resguardar-lhes um mínimo de segurança social, como exigência da dignidade da pessoa humana. ${ }^{3}$

Assim, é certo que a preocupação com a proteção contra as intempéries da vida pode ser compreendida como parte da essência humana, mas é igualmente certo que ela nem sempre foi traduzida na história da humanidade com um viés jurídico que lhe garantisse o status de direito ou como um dever a ser prestado pelo Estado, essa ideia é bem recente, na verdade. A Constituição brasileira, inspirada no modelo de Welfare State da Constituição alemã de 1919 (Constituição de Weimar) não só passou a falar em um verdadeiro dever estatal de oportunizar a concretização dos direitos sociais por meio de políticas públicas, com aporte financeiro do orçamento estatal, como o fez de modo a conferir a tais direitos um caráter de fundamentalidade exigível pelo cidadão. ${ }^{4}$

Essa capitulação tardia dos direitos sociais como pertencentes ao núcleo dos direitos fundamentais pode ser a causa da ideia errônea de que previdência e assistência sociais são meras benesses do Estado e que, por isso, podem ser contingenciadas, como se tivessem menos importância que os direitos garantidos no artigo $5^{\circ}$ da Constituição Pátria. Na verdade, não há essa hierarquia dentro do conceito de direitos fundamentais, há uma indissociabilidade no grau de importância do exercício dos direitos individuais e dos sociais, na medida em que estes são instrumentos de proteção e de concretização daqueles. ${ }^{5}$

Os direitos individuais, denominados de negativos, servem de escudo contra possíveis abusos por parte do Estado e, tendo em vista que as pessoas não vivem sozinhas no mundo, porque individualmente representam uma manifestação da sociedade, esses direitos têm íntima ligação com os direitos sociais. Os direitos chamados de positivos ou prestacionais, tais como os proporcionados pela Seguridade Social também servem de escudo, pois a sua garantia implica na legitimação dos seus institutos, como forma de contenção, sobretudo, de abusos de índole econômica. ${ }^{6}$

\footnotetext{
CUNHA JÚNIOR, Dirley da. Curso de Direito Constitucional. 7. Ed. Salvador: Jus Podivm, 2013, p. 592-594.

4 SARLET, Ingo Wolfgang. O Estado Social de Direito, a proibição de retrocesso e a garantia fundamental da propriedade. Revista Diálogo Jurídico, Salvador, ano I, v. I, n 4, jul., p. 1-22, 2001. Disponível em: http://livros-e-revistas.vlex.com.br/vid/retrocesso-fundamental-propriedade-59632193. Acesso em 20 mai 2019.

5 MARMELSTEIN, George. Curso de Direito Fundamentais. 2. ed. São Paulo: Atlas, 2014, p. 294.

6 CORREIA, Marcus Orione Gonçalves. Comentário ao artigo 193. In: CANOTILHO, J. J. Gomes; MENDES, Gilmar F.; SARLET, Ingo W.; STRECK, Lenio L. (Coords.). Comentários à Constituição do Brasil. São Paulo: Saraiva/ Almedina, p. 4080-4101, 2013. E-book.
} 
Há abuso do poder econômico quando a segurança contra as contingências sociais, que é um direito fundamental, é tratada como bem de consumo, como uma mercadoria negociável. Nesse caso, é preciso lembrar que o ideário de proteção social se encontra intrinsecamente ligado aos direitos humanos, já que é preciso haver a efetivação dos direitos sociais para que sejam preservados os direitos do homem individualmente considerado. Além disso, a expansão dos direitos fundamentais serve de parâmetro para a aferição da qualidade da democracia de uma sociedade, pois não é possível falar em democracia fortalecida, sem que os direitos fundamentais sejam reconhecidos e protegidos pelo Estado. ${ }^{7}$

Os direitos sociais são importantes fatores de estruturação da democracia nos países cujo modelo de Estado é o social e isso se dá porque o reconhecimento desses direitos estrutura o próprio princípio democrático, ao vinculá-lo à ideia de liberdade igualitária: só há realmente democracia quando todas as pessoas têm iguais possibilidades de participar no governo da polis. Só há justiça no processo de participação política (ou seja, na democracia), quando há justiça distributiva na dimensão dos bens sociais. A democracia pressupõe, assim, uma base jusfundamental inevitável, que se inicia nos direitos fundamentais da pessoa e termina nos direitos sociais, pois não é possível construir uma democracia com fome, miséria e exclusão. ${ }^{8}$

Nessa toada, resta claro que os direitos relacionados à seguridade se enquadram na categoria dos direitos que permitem que os outros direitos possam ser exercidos. Por isso se vê aqui a necessidade do seu fortalecimento como garantia do direito a se ter direitos. Se os abusos contra os direitos forem mais fortes que a sua preservação, tais abusos só serão percebidos quando os direitos se perderem e não puderem mais ser recuperados devido à nova situação instaurada. ${ }^{9}$ Como não há exercício de liberdades no desamparo, a razão de ser do direito à seguridade é assegurar a existência dos direitos individuais, bem como, assegurar a concretização da dignidade da pessoa humana, princípio maior das ordens jurídicas democráticas mundo afora.

É impossível falar em dignidade plena dentro de um país que não luta pela diminuição das desigualdades sociais com afinco. No Brasil, só uma parte da sociedade consegue reivindicar esse direito veementemente, pois o resto, mais especificamente os mais carentes, permanecem na luta pelos tantos outros direitos básicos que lhes são negados - tantos, que a dignidade passa a ter uma abstração difícil de ser por eles compreendida. E nenhuma das reivindicações pleiteadas sob a alcunha de direitos sociais

\footnotetext{
7 CUNHA JÚNIOR, Dirley da. Curso de Direito Constitucional. 7. Ed. Salvador: Jus Podivm, 2013, p. 594-596.

8 CANOTILHO, José Joaquim Gomes. O direito constitucional como ciência de direcção — O núcleo essencial de prestações sociais ou a localização incerta da socialidade (contributo para a reabilitação da força normativa da "constituição social"). In: CANOTILHO, J. J. Gomes; CORREIA, Marcus O. G.; CORREIA, Érica P. B. (Coords.). Direitos Fundamentais Sociais. 2. ed. São Paulo: Saraiva, p. 11-32, 2015, p 12.
}

9 ARENDT, Hannah. Origens do totalitarismo. São Paulo: Companhia das letras, 2012, p. 330-334. 
poderá alcançar seu objetivo sem que haja uma efetiva intervenção do Estado na economia, em prol da diminuição das desigualdades. ${ }^{10}$

Ocorre que a tentativa de ampliação dos direitos sociais, em alguns países, fere interesses que acabam por refletir na sua democracia. É o caso da Venezuela, por exemplo, que teve no governo de Hugo Chávez uma maior participação democrática em razão da utilização do lucro do petróleo no desenvolvimento de políticas sociais, com o fito de atingimento de uma maior justiça social. O governo do então presidente tinha o intuito de enfrentar a pobreza e a exclusão por meio de uma maior participação popular no processo democrático, empoderando os sujeitos políticos daquela sociedade através de políticas públicas de melhoria nas condições sociais do povo venezuelano. ${ }^{11}$

A chamada democracia participativa e protagónica instituída na Constituição de 1999 previa a criação de um Poder Cidadão e de um Poder Eleitoral, como instrumentos de fiscalização e controle da Administração Pública pelos cidadãos, além da utilização de elementos de participação direta, como plebiscitos e referendos, numa democracia baseada na força popular adquirida por conta da justiça social promovida a partir da realização dos direitos sociais, principalmente dos atinentes à seguridade social, que nesse país abarcam a assistência, a educação, a saúde e a previdência. De uma democracia pactuada, embasada no estado mínimo, isento de seu papel garantidor de direitos, a Venezuela passou para um Estado baseado numa democracia protagonizada pelo cidadão, que diminuiu taxas de pobreza, analfabetismo, indigência, desemprego, mortalidade infantil e desigualdade, bem como aumentou o acesso à saúde. ${ }^{12}$

Ao promover essa política anticapitalista, distributiva, contrária ao ideal hegemônico da burguesia venezuelana e da elite financeira internacional, o país passou a sofrer atuações internas e externas para que o sistema implantado entrasse em colapso, por meio de apoios a golpes políticos, como o sofrido por Chávez em 2002, e por embargos econômicos que minassem as fontes de riqueza do país. Foi assim que a Venezuela entrou numa crise democrática da qual não tem capacidade de sair sem o enfraquecimento das forças políticas do país e, consequentemente, das políticas públicas antes promotoras de empoderamento do cidadão, dentre elas, as que buscam reduzir desigualdades como as políticas de seguridade. ${ }^{13}$

Uma sociedade com desigualdades gritantes não consegue conferir dignidade aos indivíduos que se encontram em situação econômica desfavorável. Com isso, fica

\footnotetext{
10 BECKER, Alfredo Augusto. Teoria geral do direito tributário. 5. ed. São Paulo: Noeses, 2010, p. 166-170.

11 FUKUSHIMA, Kátia Alves. A política social do governo Chávez e a democracia venezuelana: quais os avanços? Mural Internacional, Rio de Janeiro, v. 9, n. 1, jan-jun, p. 99-121, 2018, p. 102-103.

12 FUKUSHIMA, Kátia Alves. A política social do governo Chávez e a democracia venezuelana: quais os avanços? Mural Internacional, Rio de Janeiro, v. 9, n. 1, jan-jun, p. 99-121, 2018, p. 103-110.

13 PENNAFORTE, Charles. De Chávez a Maduro: a Venezuela sob ataque contra antissistêmico?.Revista Intellector, Rio de Janeiro, v. XI, ano 21, jul-dez, p. 42-68, 2014, p. 49-55.
} 
mais perceptível a relevância que têm as políticas públicas de seguridade na promoção da real democracia, já que a sua finalidade (e dos direitos sociais em geral) é beneficiar os hipossuficientes, de modo a assegurar-lhes situação de vantagem, direta ou indireta, por meio da realização da igualdade real. ${ }^{14}$

\section{O DESMONTE DA SEGURIDADE SOCIAL}

O problema, no que tange à concretização de políticas públicas promotoras de igualdade real e, consequentemente, alcance de uma democracia forte, está no fato de que os direitos "não são dádiva divina nem frutos da natureza, porque não são auto-realizáveis nem podem ser realisticamente protegidos num estado falido ou incapacitado, [os direitos] implicam a cooperação social e a responsabilidade individual".15 Embora apenas os direitos sociais aparentem ser os que necessitam de financiamento, a concretização dos direitos fundamentais, de todos eles - sejam os individuais, sejam os sociais - demanda custos, que devem ser suportados pela sociedade, direta ou indiretamente. É aí que entra a tributação como ferramenta de arrecadação do Estado para o alcance de suas finalidades. ${ }^{16}$

É por isso que alterações na carga tributária de um país, junto a outros fatores, podem influenciar no cotidiano das pessoas de sobremaneira, gerando uma crise do Estado social que pode ser tida como uma crise de toda a sociedade. Para evitar esse tipo de crise, é preciso adaptar os sistemas de prestação estatal à economia, sem, contudo, se afastar do clamor elementar da humanidade por segurança social. ${ }^{17}$

O Brasil adotou em 1988 um tipo de arrecadação que resguarda especificamente a proteção dos indivíduos contra as contingências sociais, ao criar as contribuições de Seguridade Social e ao separar o orçamento desse setor dos demais: segundo $\$ 5^{\circ}$ do artigo 165, a lei orçamentária anual deve compreender os orçamentos fiscal, de investimentos e da Seguridade Social. Assim é que o orçamento, que é uno, em atendimento ao princípio da unidade, promove a integração finalística e a harmonização dos três orçamentos dentro de uma única lei. ${ }^{18}$

Conforme a determinação constitucional, o produto da arrecadação advinda das citadas contribuições deveria ingressar diretamente no orçamento da Seguridade

14 BONAVIDES, Paulo. Teoria constitucional da democracia participativa. 3. ed. São Paulo: Malheiros, 2008, p. 157.

15 NABAIS, José Casalta. A face oculta dos direitos fundamentais: os deveres e os custos dos direitos. Revista Direito Mackenzie, São Paulo, v. 3, n. 2, p. 9-30, 2002, p. 20.

16 NABAIS, José Casalta. O dever fundamental de pagar impostos: contributo para a compreensão do estado fiscal contemporâneo. Coimbra: Livraria Almedina, 2009, p. 59.

17 SUNSTEIN, Cass. The cost of rigths - Why liberty depends on taxes. New York: Norton, 1999, p. 15.

18 TORRES, Ricardo Lobo. Comentário ao artigo 165. In: CANOTILHO, J. J. Gomes; MENDES, Gilmar F.; SARLET, Ingo W.; STRECK, Lenio L. (Coords.). Comentários à Constituição do Brasil. São Paulo: Saraiva/Almedina, p. 3761-3796, 2013, E-book, p. 3771. 
e, em seu texto original, a Constituição previa que estas exações seriam cobradas especificamente pela entidade responsável pela sua gestão, o Instituto Nacional do Seguro Social - INSS. Dita autarquia, criada para a gerência do orçamento securitário não é mais sujeito ativo na relação tributária desde 2007, quando passou a ficar a cargo da chamada "Super Receita"19 a arrecadação de todos os tributos feitos pela União, inclusive as contribuições de Seguridade Social, afetando, assim, a finalidade da separação dos orçamentos de evitar a confusão de receitas. ${ }^{20}$

Embora não haja mais discussão nos tribunais superiores acerca desse alargamento de atribuições, posto que pacificado o entendimento no STF a favor da constitucionalidade da lei de criação da "Super Receita", é possível defender a tese da flagrante inconstitucionalidade da transferência de sujeito ativo das contribuições do INSS para a Receita Federal, pois as contribuições que financiam diretamente a seguridade social não poderiam constituir receita do Tesouro Nacional. Elas devem ingressar diretamente no orçamento securitário, sob pena de violação da autonomia assegurada constitucionalmente à atividade de seguridade social. Ademais, é constitucionalmente reservada à lei complementar a tratativa da gestão financeira e patrimonial da Administração Pública direta e indireta, não a uma lei ordinária. ${ }^{21}$

Afora essa questão relativa ao sujeito ativo, mesmo havendo uma separação fidedigna das receitas pertencentes ao tesouro nacional e à seguridade social, o orçamento securitário ainda sofre um desfalque de suas receitas com a Desvinculação de Receitas da União, a DRU. No início, a desvinculação era de $20 \%$ dos recursos e passou, no ano de 2016, a 30\% do que deveria ser destinado à concretização das políticas da seguridade social. ${ }^{22}$

Importante ressaltar que a característica de serem tributos finalísticos é o que define as contribuições sociais com maior propriedade. ${ }^{23}$ Não fosse isso, ficaria difícil diferenciá-las das demais espécies tributárias. A característica da vinculação da sua arrecadação ao mantimento da Seguridade Social é tão importante, que é possível ao contribuinte recusar-se ao pagamento da contribuição social que não respeite

19 A terminologia "Super Receita" não foi conferida pelo legislador, mas é usualmente adotada pelo governo e pela doutrina, em função da gama de funções atribuídas a esse órgão a partir da Lei no 11.457/07.

20 MACHADO, Hugo de Brito. Curso de Direito Tributário. 37. ed. São Paulo: Malheiros, 2016, p. 428-429.

21 MACHADO, Hugo de Brito. Curso de Direito Tributário. 37. ed. São Paulo: Malheiros, 2016, p. 429.

22 SALVADOR, Evilasio da Silva. O desmonte do financiamento da seguridade social em contexto de ajuste fiscal. Serviço Social \& Sociedade. São Paulo, n 130, set-dez, p. 426-446, 2017. Disponível em: http://dx.doi. org/10.1590/0101-6628.117. Acesso em 04 jun 2019.

23 Na opinião de MACHADO, Hugo de Brito. Curso de Direito Tributário. 37. ed. São Paulo: Malheiros, 2016; IBRAHIM, Fábio Zambitte. Curso de Direito Previdenciário, 16. ed. Niterói: Impetus, 2011; PAULSEN, Leandro. Direito Tributário - Constituição e Código Tributário à luz da doutrina e da jurisprudência. 15. ed. Porto Alegre: Livraria do Advogado, 2013; TORRES, Ricardo Lobo. Curso de Direito Financeiro e Tributário. 18. ed. Rio de Janeiro: Renovar, 2011; MARTINS, Sérgio Pinto. Direito da Seguridade Social. 36. ed. São Paulo: Saraiva, 2016; HARADA, Kiyoshi. Direito Financeiro e Tributário. 25. ed. São Paulo: Atlas, 2016; e COÊLHO, Sacha Calmon Navarro. Curso de Direito Tributário Brasileiro. 15. ed. Rio de Janeiro: Forense, 2016. 
a destinação constitucionalmente estipulada para as receitas obtidas a partir do seu pagamento. $^{24}$

A desvinculação transforma os recursos destinados ao financiamento da seguridade social em recursos fiscais, que são utilizados na composição do superávit primário, para, finalmente, pagar juros da dívida. Desse modo, fica difícil seguir o propósito do constituinte originário de salvaguardar o direito à proteção social através das contribuições sociais e, até mesmo, entender esses tributos como sendo realmente finalísticos. ${ }^{25}$

Como se vê, na prática, o que importa é saber se a arrecadação proveniente das contribuições sociais é vertida corretamente para a área estipulada pela Constituição. Não sendo, elas perdem a sua característica da vinculação, deixam de ser contribuição e, por fim, deixam de ser exigíveis. O que dizer, então, da parte do que é arrecadado com o PIS, com a COFINS e com a CSLL, por exemplo, que não é destinado à Seguridade Social, em razão da DRU?

OSTF já se posicionou pela constitucionalidade da DRU, o que causa estranheza, tendo em vista que, no sistema pátrio, os direitos sociais (dentre os quais se encontra a seguridade social) receberam não só "status" constitucional, mas fundamentalidade material e formal. Haveria nesse sequestro de verbas, portanto, evidente violação da cláusula pétrea contida no art. $60, \S 4^{\circ}$, IV, bem como descumprimento do princípio implícito da vedação ao retrocesso social. ${ }^{26}$

Talvez, numa interpretação estritamente literal da Constituição, não coubesse se falar na inclusão do direito à previdência pública como cláusula imutável. Todavia, uma leitura sistêmica do texto demonstra que não há hierarquia entre os direitos de defesa e os prestacionais, onde se enquadra o seguro social público. Ao contrário disso, percebe-se uma sintonia entre o legislador constituinte e a ideia de indivisibilidade e interdependência dos direitos fundamentais. A moderna hermenêutica jurídica entende, portanto, que o constituinte conferiu o status de cláusula pétrea a esse direito também, pois conferiu tal status a todos os direitos fundamentais. ${ }^{27}$

Questões como a definição do sujeito ativo arrecadador das contribuições e a DRU são problemas que afetam a robustez do sistema de segurança social brasileiro, mas, como visto, já são temas pacificados no Supremo Tribunal Federal. Existem ainda outros desvios que afetam o orçamento securitário, sem que sua constitucionalidade

24 DERZI, Misabel Abreu Machado. In: BALEEIRO, Aliomar. Direito Tributário Brasileiro, atualização de. 11. ed. Rio de Janeiro: Forense, 2008, p. 69.

25 IBRAHIM, Fábio Zambitte. Curso de Direito Previdenciário, 16. ed. Niterói: Impetus, 2011, p. 117-123.

26 FERRAZ, Fernando Basto et al. A desvinculação das receitas da união (DRU) e a efetivação de direitos fundamentais sociais. In: Direitos fundamentais sociais na contemporaneidade, São Paulo: LTr, p. 15-30, 2014. Disponível em https://app.vlex.com/\#BR/vid/53741 1946. Acesso em: 04 jun 2019.

27 SARLET, Ingo Wolfgang. Comentário ao artigo 60. In: CANOTILHO, J. J. Gomes; MENDES, Gilmar F.; SARLET, Ingo W.; STRECK, Lenio L. (Coords.). Comentários à Constituição do Brasil. São Paulo: Saraiva/Almedina, p. 1213-1226, 2018, p. 1224. 
tenha sido discutida. São eles: a política de desonerações fiscais, que afetam diretamente os tributos que compõem a sua base de custeio, e o desvio de finalidade das contribuições de seguridade social.

A política de desonerações de tributos promovida pelo governo federal para estimular o investimento privado tem como objetivo uma maior geração de empregos e uma melhora nas condições de competitividade do mercado nacional (particularmente da indústria nacional). No entanto, a renúncia de receitas não tem surtido efeitos relevantes, já que o Estado não exigiu que as empresas beneficiadas demonstrassem resultados específicos em favor da sociedade, tais como: geração de emprego, garantia de direitos trabalhistas, proteção ambiental, entre outros. Com desonerações nesses termos, a sociedade perdeu recursos e não ganhou em nenhum outro aspecto. ${ }^{28}$

As desonerações não são integralmente compensadas pelo tesouro com relação ao PIS/PASEP e, a partir de 2008, passaram a retirar das receitas do Fundo de Amparo ao Trabalhador - FAT o equivalente a uma nova DRU por ano. Ironicamente, boa parte dos grupos desonerados, como o da construção civil, da indústria petroquímica e a de medicamentos, são responsáveis por grande parte dos gastos do FAT com o pagamento de seguro-desemprego. ${ }^{29}$ Não se admira saber que as regras de concessão de seguro-desemprego foram alteradas em 2014 para dificultar a sua percepção pelo trabalhador. Com um orçamento violado nessas proporções, a Seguridade ganha a pecha de insustentável por não dispor de recursos suficientes para a sua manutenção, ao mesmo tempo em que a classe trabalhadora desamparada perde força na luta contra a apatia política que a domina, por ter de conviver com dificuldades outras, que a "simples" participação na vida política do país.

Outro tributo fortemente afetado com as desonerações é a COFINS, cujas renúncias fiscais representavam 6,0\% da sua receita em 2005, 20,5\% em 2008 e 32,1\% da sua arrecadação em 2015. É temeroso que um terço da arrecadação desse tributo esteja comprometido com as renúncias fiscais, quando é cediço que a cobertura estatal das desonerações para o orçamento da Seguridade é insuficiente, ante o volume de renúncias tributárias gerais. ${ }^{30}$

28 GENTIL, Denise Lobato et al. Uma análise não convencional para o financiamento da Previdência Social no Brasil: aspectos teóricos e evidências empíricas. In: PUTY, Cláudio Alberto Castelo Branco; GENTIL, Denise Lobato (Org.). A Previdência Social em 2060: As inconsistências do modelo de projeção atuarial do governo brasileiro. Brasília: ANFIP/DIEESE, 2017, p. 48.

29 OLIVEIRA, Thiago e FERRAZ, Alexandre. Programa Seguro-desemprego: qual a reforma necessária? Revista Política Social e Desenvolvimento, [s.I.], p. 28-37 dez. 2015. As demandas sociais da democracia não cabem no orçamento? Parte II. Disponível em: https://revistapoliticasociale desenvolvimento.com/2015/12/24/a-democracia-nao-cabe-no-orcamento-parte-ii/. Acesso em 23 ago 2017.

30 ASSOCIAÇÃO NACIONAL DOS AUDITORES-FISCAIS DA RECEITA FEDERAL DO BRASIL E FUNDAÇÃO ANFIP DE ESTUDOS DA SEGURIDADE SOCIAL E TRIBUTÁRIO. Análise da Seguridade Social 2015. 16. ed. Brasília: ANFIP, 2016, p. 53. 
A desoneração total de tributos possui números significativos, principalmente se comparados ao alegado rombo previdenciário, como bem se vê: em 2009 foram R\$ 119,8 bilhões, em 2011 subiu para R\$ 137,2 bilhões e em 2015, o montante de R\$ 282,4 bilhões ${ }^{31}$. Tais valores, no entanto, não se restringem aos tributos mantenedores especificamente da Seguridade Social, mas representam mais da metade das renúncias de receita do governo federal. Assim, constatamos que há margem para um aumento na arrecadação de receitas da Seguridade Social por meio da revisão das renúncias de contribuições sociais. ${ }^{32}$

O que se vê com isso, então, é a mera disposição de verbas públicas em prol do setor privado, sem que se tenha demandado desse setor qualquer tipo de contrapartida pela perda de receitas que deveriam ter sido aplicadas no financiamento de políticas públicas. Como consequência, a Seguridade Social, já tão molestada com uma arrecadação ineficiente, repasses insuficientes e desonerações, ainda tem que enfrentar a alegação de que um dos seus ramos, a Previdência, é deficitária e precisa ser reformulada ${ }^{33}$.

Diante da atual conjectura e das constantes propostas de reforma da Previdência, sob uma alegada impossibilidade financeira do Estado em arcar com tais direitos sociais, os desvios que acometem o orçamento securitário parecem ser esquecidos pela sociedade. Sob a justificativa de que o Estado prestacional se tornou ineficiente, gastador e causador de déficit público, observamos a tentativas constantes de "comoditização" do direito à seguridade social, mais especificamente do direito à previdência pública, sem nos atentarmos para a sua essencialidade na concretização dos objetivos fundamentais da República e para o ganho de força da democracia, a partir do empoderamento social dos autores políticos. ${ }^{34}$

Daí a imprescindibilidade do fortalecimento desse aspecto do direito à seguridade como dever público, dentro do modelo de Estado de Bem-Estar Social proposto pela Constituição Federal, para a promoção da justiça social no país. A precarização da

31 Essa quantia é maior do que a soma de tudo o que foi gasto, na esfera federal, com Saúde (R\$̣93 bilhões), Educação (R\$93,9 bilhões), Assistência Social (R\$1 bilhões), Transporte ( $R \$ 13,8$ bilhões) e Ciência e Tecnologia (R\$6,1 bilhões) no ano de 2014. Dados do Ministério do Planejamento, SOF, Despesa Orçamentária por Agregados Funcionais e Programáticos (GENTIL, Denise Lobato et al. Uma análise não convencional para o financiamento da Previdência Social no Brasil: aspectos teóricos e evidências empíricas. In: PUTY, Cláudio Alberto Castelo Branco; GENTIL, Denise Lobato (Org.). A Previdência Social em 2060: As inconsistências do modelo de projeção atuarial do governo brasileiro. Brasília: ANFIP/DIEESE, 2017, p. 48).

32 GENTIL, Denise Lobato et al. Uma análise não convencional para o financiamento da Previdência Social no Brasil: aspectos teóricos e evidências empíricas. In: PUTY, Cláudio Alberto Castelo Branco; GENTIL, Denise Lobato (Org.). A Previdência Social em 2060: As inconsistências do modelo de projeção atuarial do governo brasileiro. Brasília: ANFIP/DIEESE, 2017, p. 48.

33 ASSOCIAÇÃO NACIONAL DOS AUDITORES-FISCAIS DA RECEITA FEDERAL DO BRASIL E FUNDAÇÃO ANFIP DE ESTUDOS DA SEGURIDADE SOCIAL E TRIBUTÁRIO. Análise da Seguridade Social 2015. 16. ed. Brasília: ANFIP, 2016, p. 25-32.

34 FALEIROS, Vicente de Paula. A política social do Estado Capitalista, 8. ed. São Paulo: Cortez, 2000, p. 8793. 
Seguridade Social tem um viés neoliberalista e as reformas pretendidas pelo governo, a partir dessa precarização, atendem a uma parcela (muito pequena) da sociedade: apenas aquela que vê na previdência e na saúde privadas um nicho de mercado promissor, posto que extremamente lucrativo.

\section{A FRAGILIZAÇÃO DA DEMOCRACIA PELA VIA SOCIAL}

O custeio tríplice e a diversidade de fatos da vida tributáveis pelas contribuições de Seguridade Social foram idealizados justamente para que não houvesse desculpa para a não concretização dos direitos sociais abarcados pelo sistema securitário. A Constituição tem caráter predominantemente social, protecionista, tendo em vista a experiência passada com a ditadura militar, que abusou da arrecadação securitária em prejuízo do povo brasileiro, pois, ao invés de a política econômica financiar a política social, acontecia o contrário e a política social acabava financiando a política econômica. Importante ressaltar que essa lógica invertida continuou sendo utilizada nos governos democráticos brasileiros a partir de 1990.35

Sob uma perspectiva jurídica e econômica, é cediço que os recursos orçamentários auferidos por meio da tributação não são infinitos (são, na verdade, escassos), enquanto as necessidades humanas são ilimitadas. Daí a necessidade de concertar essa tributação com os objetivos da República, para que os recursos advindos da tributação sejam empregados de modo eficiente, sempre objetivando o atendimento do maior número de necessidades possível. É preciso almejar o ápice da eficiência, pois o desperdício e a ausência de foco na maximização dos recursos orçamentários para a sua utilização social, gera injustiça inaceitável. ${ }^{36}$

A vinculação dos tributos à consecução dos direitos fundamentais é corolário do princípio da solidariedade, que norteia o Direito Previdenciário e serve de fundamento para a tributação que busca alcançar a justiça social. A solidariedade em questão é a distributiva, que pressupõe a existência de desigualdade de forma a justificar a atuação do Estado em favor dos mais desfavorecidos, independentemente de haver possibilidade de invocação de reciprocidade. ${ }^{37}$

35 FAGNANI, Eduardo. A Previdência Social não tem déficit. Revista Política Social e Desenvolvimento, [s.l.], p. 14-21, dez. 2015. As demandas sociais da democracia não cabem no orçamento? Parte II. Disponível em http://plataformapoliticasocial.com.br/wp-content/uploads/2016/02/Revista_28.pdf. Acesso em 23 ago 2017.

36 TIMM, Luciano Benetti. Qual a maneira mais eficiente de prover direitos fundamentais: uma perspectiva de direito e economia?. In: SARLET, Ingo Wolfgang; TIMM, Luciano Benetti (Org.) Direitos Fundamentais - orçamento e "reserva do possível". Porto Alegre: Livraria do Advogado, p. 51-62, 2010, p. 56-60.

37 TAVARES, Marcelo Leonardo e SOUSA, Ricardo José Leite. O Princípio Da Solidariedade Aplicado À Previdência Social. Revista Jurídica (0103-3506), [s. I.], v. 1, n. 42, p. 277-293, 2016. Disponível em: http://search. ebscohost.com/login.aspx?direct=true\&db=foh\&A $\mathrm{N}=113852823 \&$ lang=pt-br\&site =eds-live. Acesso em 11 jun 2019. 
A tributação que se concretiza o princípio da solidariedade repercute na formação das classes sociais, servindo de base para o Estado promover uma redistribuição do capital e da renda entre as pessoas. O Direito Tributário tem uma função maior de realizar essa revolução social, se valendo do tributo não só como instrumento de arrecadação, mas também de intervenção no meio social, para o atingimento de outros direitos básicos, intrínsecos ao ser humano, entre eles os direitos políticos inerentes à vida dentro de um Estado Democrático de Direito. ${ }^{38}$

É comum que se busque que a arrecadação fiscal se mostre mais incisiva sobre os mais ricos, ou seja, sobre aqueles que apresentem maior capacidade contributiva. Além de tentar deter as desigualdades sociais, arrecadando mais daqueles com maior capacidade contributiva, a solidariedade embasa uma tributação que serve como método de formação de capital estatal suficiente para a condução e efetivo financiamento de políticas públicas que fomentem a cidadania. ${ }^{39}$

Sob uma visão bem superficial do tributo com esse propósito de colocar fim às desigualdades sociais, pode até parecer plausível a ideia de que é a tributação elevada que subsidia a solidariedade e promove a distribuição de renda geradora de justiça social, no entanto, a realidade não é bem essa. O Brasil, país com alta arrecadação fiscal, frequentemente se encontra em posição desfavorável no relatório das Nações Unidas que mede do desenvolvimento humano.

A título de exemplo, tomemos o ano de $2017^{40}$, quando a carga tributária do Brasil chegou a 32,29\%: o país ocupou a 79a posição no índice de desenvolvimento humano da ONU - IDH ${ }^{41}$. Enquanto isso, países como Noruega, Canadá, Suíça e Estados Unidos apresentaram uma carga de 38\%, 31,7\%, 27,8\% e 26\%, respectivamente, e posições altas no IDH: 1a $12^{\mathrm{a}}$, $2^{\mathrm{a}}$ e $13^{\mathrm{a}}$ posições, respectivamente. No quesito fiscal, o Brasil está dentro da média da OCDE, que foi de $34,3 \%$ do PIB, no citado ano, mas ainda assim a tributação é bastante alta, tendo em vista o baixo retorno de bem-estar social que representa. No quesito participação popular, o índice democrático proposto pela revista The Economist ${ }^{42}$ lista o Brasil dentre os países com democracia falha ou imperfeita, em razão, principalmente, da ineficiência das instituições, enquanto os países acima citados estão todos dentre os países com democracia plena. A Noruega, país que encabeça

38 BECKER, Alfredo Augusto. Teoria geral do direito tributário. 5. ed. São Paulo: Noeses, 2010, p. 10.

39 PIKETTY, Thomas. O capital no século XXI. Ed digital. Rio de Janeiro: Intrínseca, 2014, p. 607.

40 Segundo dados da Receita Federal brasileira, que trouxe a média da carga tributária de cada um dos países integrantes da OCDE. Disponível em: http://receita.economia.gov.br/dados/receitadata/estudos-e-tributarios-e-aduaneiros/estudos-e-estatisticas/carga-tributaria-no-brasil/carga-tributaria-2017.pdf. Acesso em: 03 junho 2019.

41 Conforme Relatório das Nações Unidas publicado em 2018, referente ao ano de 2017. Disponível em: http://hdr.undp.org/sites/default/files/2018_human_development_statistical_update.pdf. Acesso em: 03 junho 2019.

42 Segundo dados da Democracy index list da revista. Disponível em: https://infographics.economist. com/2019/Democracylndex/ Acesso em: 14 jun 2019. 
a lista dos países plenamente democráticos no mundo, segundo a revista, é também o que possui o mais alto índice de desenvolvimento humano, com uma carga tributária superior à brasileira. Onde está o problema, então, se não está na tributação?

O problema é histórico e está na condução das políticas públicas, na distribuição dos recursos e vontade política de transformação social do país. O modelo constitucional instituído no Brasil de 1988 esbarra no receituário neoliberal em voga desde os anos 70 na América Latina. Nesse período e nas décadas seguintes, propugnou-se por uma política de diminuição estatal, com cortes nas despesas destinadas às políticas sociais e investimentos, reformulações das leis previdenciárias, flexibilização do mercado financeiro em benefício de bancos internacionais, programas de privatizações e desregulamentação das relações de trabalho, entre outras pautas neoliberais, tudo sob a alegação de que o financiamento do Welfare State tinha saído caro demais à sociedade. ${ }^{43}$

Dentro desse contexto, o Brasil entrou num período de redemocratização e de um Estado social bem teorizados na Lei Maior do país, já com o primeiro presidente eleito depois de anos de ditadura acolhendo a doutrina desse neoliberalismo que tomava conta da América Latina. A contradição entre teoria constitucional e prática política seguiu em frente na eleição seguinte, quando, depois de Fernando Collor de Mello (na época no PRN), foi eleito presidente Fernando Henrique Cardoso (PSDB) para mais dois mandatos. O neoliberalismo constava na agenda política de ambos, mas foi aplicado de forma mais efetiva no governo do segundo, momento em que se teve a privatização de um grande número de empresas públicas, supostamente geradoras de despesa, em prol da solvabilidade das contas públicas. ${ }^{44}$

A crise financeira - ou de financiamento - do Estado parece ser o legado do insucesso do Welfare State, entretanto, países como o Brasil não atingiram o nível de proteção social do Welfare State, como atingiram os países precursores de tais ideias. Daí chegarmos à conclusão que a redução de gastos públicos com políticas sociais significa, na verdade, o reconhecimento do não atingimento do Bem-Estar Social prometido $^{45}$. A volta da doutrina do liberalismo no país, portanto, parece estar mais associada a um projeto de poder que acaudilha a política dos países latino-americanos, para se

\footnotetext{
43 GOMES, Cláudia Maria Costa e ROJAS, Gonzalo Adrián. Crise orgânica, governos e seus impactos na América Latina. Em Pauta - Revista da Faculdade de Serviço Social da Universidade do Estado do Rio de Janeiro, Rio de Janeiro, n. 39, v. 15, 10 Semestre, p. 17-32, 2017, p. 26.

44 BRANDÃO, Leonardo e SILVA, Michel Honório da. A emergência do neoliberalismo no Brasil: um estudo sobre a revista Veja no contexto das eleições presidenciais de 1989. Revista Estudos em Comunicação, [s.I.], n. 24, p. 27-42, 2017, p. 28.

45 CASTRO, Carlos Alberto Pereira de e LAZZARI, João Batista. Direito Previdenciário. Rio de Janeiro: Forense, 2016, p. 36-40. E-book.
} 
manterem sempre numa relação subordinada aos países capitalistas centrais, do que ao insucesso do Estado prestacional. ${ }^{46}$

Esse movimento de neoliberalismo procura reduzir o tamanho e as funções sociais do Estado, atacando-o com o objetivo implícito de enfraquecê-lo. A empreitada parece visar uma volta ao tempo do Estado Liberal do século XIX, onde vigia um Estado não democrático, com uma burguesia com maiores poderes do que os que tem hoje no Estado Democrático. Isso porque apenas os direitos civis precisam ser garantidos no Estado Liberal, não os sociais, e nem mesmo os políticos, já que, por se opor ao sufrágio universal, é modelo de estado que não guarda congruência com a democracia. ${ }^{47}$

Há aí um contraste óbvio com o que preconiza a Constituição Cidadã, que universalizou os direitos políticos, conferindo o direito de voto inclusive aos analfabetos (mesmo que facultativamente) e ampliou significativamente os direitos sociais. Alega-se, no entanto, que o avanço constitucional realizado pela democracia não resolveu os problemas sociais, não diminuiu a pobreza e não conseguiu reduzir as desigualdades, ou seja, não concretizou os direitos sociais como intentou o constituinte de $1988 .{ }^{48}$

Vale lembrar que são as políticas públicas de concretização dos direitos sociais, erigidos à categoria de direitos fundamentais por essa mesma constituição, as principais responsáveis por garantir as bases de uma democracia fortalecida, pois onde há desigualdade não há real democracia. Elas são, ainda, os instrumentos de concretização dos objetivos visados pela nação, refletindo as metas coletivas mais relevantes dentro de uma sociedade. ${ }^{49}$

É porque a pobreza e as desigualdades sociais provocam um abismo de injustiças, que todas as políticas sociais possuem o objetivo último de alcance da Justiça Social. O alvo principal desse objetivo pode ser sintetizado no artigo $3^{\circ}$ da Constituição, o qual afirma ser objetivo fundamental da nação dar aos seus cidadãos condições de viver em uma sociedade justa, livre, sem desigualdades sociais e regionais, pobreza ou marginalização, prezando, como consequência final, pelo bem de todos, e é isso que vai permitir que o país se desenvolva..$^{50}$

\footnotetext{
46 GOMES, Cláudia Maria Costa e ROJAS, Gonzalo Adrián. Crise orgânica, governos e seus impactos na América Latina. Em Pauta - Revista da Faculdade de Serviço Social da Universidade do Estado do Rio de Janeiro, Rio de Janeiro, n. 39, v. 15, 10 Semestre, p. 17-32, 2017, p. 24.

47 BRESSER-PEREIRA, Luiz Carlos. Democracia, estado social e reforma gerencial. Revista de administração de empresas, São Paulo, v. 50, n. 1, p. 112-116, 2010. Disponível em: http://www.scielo.br/scielo.php?script=sci_arttext\&pid=S0034-75902010000100009\&Ing=en \&nrm=iso. Acesso em 15 jun 2019.

48 CARVALHO, José Murilo de. Cidadania no Brasil - o longo caminho. Rio de Janeiro: Civilização brasileira, 2001, p. 206-225.

49 GARCIA, Maria. Políticas públicas e normas programáticas: a efetividade da Constituição, a Administração Pública e o Estado de Direito. In: GARCIA, Maria (Coord.). Revista de Direito Constitucional e Internacional. São Paulo, v. 19, n. 76, jul-set, p. 101-112, 2011.

50 BALERA, Wagner. Sistema de Seguridade Social. São Paulo: LTR, 2014. E-book. Disponível em: https://app. vlex.com/\#sources/12806. Acesso em 15 jun 2019.
} 
Bem-estar e justiça sociais, inclusive, são claramente os fins últimos da Ordem Social estabelecida na Constituição Federal de 1988, conforme se depreende da literalidade do artigo 193. Nesse aspecto, a seguridade social revela ter certa prioridade no Brasil, por ser o primeiro dos direitos sociais tratados no citado título e por ser o direito que mais está ligado ao combate das desigualdades, a partir de uma tributação incisiva sobre receita, faturamento e lucro do setor produtivo do país em benefício dos vulneráveis em geral e, principalmente, trabalhadores.

A Constituição estruturou a Seguridade Social, com orçamento próprio, como um conjunto integrado de ações de iniciativa dos poderes públicos e da sociedade, destinada a assegurar os direitos relativos à saúde, à previdência e à assistência social (artigo 194), com o fito de efetivar a cidadania do povo brasileiro. Conforme afirmou Ulisses Guimarães, ao discursar na promulgação da Carta de 1988, o homem é problema da sociedade, pois sem salário, educação, saúde e moradia, não há cidadania. Ademais, o estado de direito, como consectário da igualdade, não pode aceitar conviver com o estado de miséria, deve envidar esforços para acabar com ela. ${ }^{51}$

Tendo como mote o resgate da "dívida social" do país, a fim de aproximar a sociedade brasileira das conquistas civilizatórias das democracias mais avançadas, a classe política do período da redemocratização tinha em mente uma aproximação do crescimento econômico com o desenvolvimento social. Na verdade, a política econômica só faria sentido com a incorporação de uma vasta estratégia de desenvolvimento social, que se concretizaria a partir das políticas públicas, especialmente as de assistência, previdência e saúde públicos. ${ }^{52}$

Partindo-se da premissa de que a questão é mais social do que efetivamente econômica, é preciso que o Estado promova políticas públicas que garantam essa real melhoria de vida citada acima, alargando as liberdades, para que, repetimos, sejam ampliadas as condições de desenvolvimento da sociedade e, assim a democracia possa ser exercida na sua plenitude. Uma dessas liberdades que devem ser fomentadas pelo Estado é a de o indivíduo ter condições de evitar privações, com ênfase na importância da seguridade social, como instrumento de política pública responsável pelo resguardo dos vulneráveis e como meio de impedir que estes sejam levados à miséria extrema. ${ }^{53}$

No que tange às conquistas de direitos, mesmo não tendo alcançado o grau máximo prometido na Constituição, é certo que chegamos em um ponto de não retorno.

\footnotetext{
51 GUIMARÃES, Ulisses. Discurso na sessão de encerramento dos trabalhos da Assembleia Nacional Constituinte. Brasília, 5 out. 1988. Disponível em: https://www2.camara.leg.br/atividade-legislativa/plenario/discursos/escrevendohistoria/25-anos-da-constituicao-de-1988/constituinte-19871988/pdf/Ulysses\%20Guimaraes\%20-\%20DISCURSO\%20\%20REVISADO.pdf. Acesso em: 20 junho 2019.

52 GIMENEZ, Denis Maracci. Democracia e a Previdência Social no Brasil. Carta Social e do Trabalho, Campinas, n. 33, jan./jun., p. 59-68, 2016.

53 SEN, Amartya. Desenvolvimento como liberdade. 1. ed. 5. reimpressão. São Paulo: Companhia de bolso, 2016, p. 16.
} 
Uma volta às bases do Estado Mínimo é impensável, contudo, não se pode olvidar que é possível fazer uma reavaliação dos sistemas de arrecadação, para a busca da maximização do seu produto na aplicação da manutenção do Estado. ${ }^{54}$

\section{CONSIDERAÇÕES FINAIS}

A proteção social abordada como simples benesse estatal, e não como um direito fundamental tão importante quanto os direitos individuais, corre o risco de se passar por apenas mais um instrumento gerador de déficit orçamentário. É sabido que a seguridade compreendida assim facilita a aceitação popular de reformas que visem o corte de gastos e a "comoditização" da proteção social, em prol de interesses neoliberais.

A tributação em geral não existe como um fim em si mesmo, existe para assegurar o pacto social e todos os direitos e deveres que advém desse compromisso. O finalismo das contribuições de Seguridade Social foi estipulado constitucionalmente como uma segurança maior da utilização do produto da sua arrecadação para a elevação do bem-estar social e desvirtuar seu sentido fere de sobremaneira o sentimento de união que deve prevalecer dentro da sociedade. Por isso, o direito à seguridade deve ser fortalecido, de forma que os representantes do povo compreendam a sua importância e passem a priorizá-lo para que o Estado possa crescer não só economicamente, mas também - e principalmente - em qualidade de vida, para que a população brasileira possa exercer a democracia em maiores condições de igualdade e qualidade de vida.

A solvabilidade do Estado não pode ser desprezada, isso é certo. No entanto, tendo a seguridade como um direito fundamental e essencial para a promoção da justiça, antes de buscar a reforma do sistema de concessão de benefícios previdenciários, é necessário que se busque a maximização das receitas existentes. Ademais, evitar desvios na arrecadação do orçamento da Seguridade Social é um imperativo constitucional e de retidão administrativa.

\section{REFERÊNCIAS}

ASSOCIAÇÃO NACIONAL DOS AUDITORES-FISCAIS DA RECEITA FEDERAL DO BRASIL E FUNDAÇÃO ANFIP DE ESTUDOS DA SEGURIDADE SOCIAL E TRIBUTÁRIO. Análise da Seguridade Social 2015. 16. ed. Brasília: ANFIP, 2016.

ARENDT, Hannah. Origens do totalitarismo. São Paulo: Companhia das letras, 2012.

BALERA, Wagner. Sistema de Seguridade Social. São Paulo: LTR, 2014. E-book. Disponível em: https://app.vlex.com/\#sources/12806. Acesso em: 15 jun 2019.

54 STRECK, Lênio Luiz; MORAIS, José Luiz Bolzan de. Ciência política e teoria do estado. 3. ed. Porto Alegre: Livraria do Advogado,2003. 
BECKER, Alfredo Augusto. Teoria geral do direito tributário. 5. ed. São Paulo: Noeses, 2010.

BONAVIDES, Paulo. Teoria constitucional da democracia participativa. 3. ed. São Paulo: MaIheiros, 2008.

BRANDÃO, Leonardo e SILVA, Michel Honório da. A emergência do neoliberalismo no Brasil: um estudo sobre a revista Veja no contexto das eleições presidenciais de 1989. Revista Estudos em Comunicação, [s.I.], n. 24, p. 27-42, 2017.

BRESSER-PEREIRA, Luiz Carlos. Democracia, estado social e reforma gerencial. Revista de administração de empresas, São Paulo, v. 50, n. 1, p. 112-116, 2010. Disponível em: http://www.scielo.br/scielo.php?script=sci_arttext\&pid=S0034-75902010000100009\&lng=en \&nrm=iso. Acesso em: 15 jun 2019.

CANOTILHO, José Joaquim Gomes. O direito constitucional como ciência de direcção — O núcleo essencial de prestações sociais ou a localização incerta da socialidade (contributo para a reabilitação da força normativa da "constituição social"). In: CANOTILHO, J. J. Gomes; CORREIA, Marcus O. G.; CORREIA, Érica P. B. (Coords.). Direitos Fundamentais Sociais. 2. ed. São Paulo: Saraiva, p. 11-32, 2015.

CARVALHO, José Murilo de. Cidadania no Brasil - o longo caminho. Rio de Janeiro: Civilização brasileira, 2001.

CASTRO, Carlos Alberto Pereira de e LAZZARI, João Batista. Direito Previdenciário. Rio de Janeiro: Forense, 2016. E-book.

COÊLHO, Sacha Calmon Navarro. Curso de Direito Tributário Brasileiro. 15. ed. Rio de Janeiro: Forense, 2016.

CORREIA, Marcus Orione Gonçalves. Comentário ao artigo 193. In: CANOTILHO, J. J. Gomes; MENDES, Gilmar F.; SARLET, Ingo W.; STRECK, Lenio L. (Coords.). Comentários à Constituição do Brasil. São Paulo: Saraiva/Almedina, p. 4080-4101, 2013. E-book.

CUNHA JÚNIOR, Dirley da. Curso de Direito Constitucional. 7. Ed. Salvador: Jus Podivm, 2013.

DERZI, Misabel Abreu Machado. In: BALEEIRO, Aliomar. Direito Tributário Brasileiro, atualização de. 11. ed. Rio de Janeiro: Forense, 2008.

FAGNANI, Eduardo. A Previdência Social não tem déficit. Revista Política Social e Desenvolvimento, [s.I.], p. 14-21, dez. 2015. As demandas sociais da democracia não cabem no orçamento? Parte II. Disponível em http://plataformapoliticasocial.com.br/wp-content/uploads/2016/02/Revista_28.pdf.

FALEIROS, Vicente de Paula. A política social do Estado Capitalista, 8. ed. São Paulo: Cortez, 2000 . 
FERRAZ, Fernando Basto et al. A desvinculação das receitas da união (DRU) e a efetivação de direitos fundamentais sociais. In: Direitos fundamentais sociais na contemporaneidade, São Paulo: LTr, p. 15-30, 2014. Disponível em https://app.vlex.com/\#BR/vid/537411946.

FUKUSHIMA, Kátia Alves. A política social do governo Chávez e a democracia venezuelana: quais os avanços? Mural Internacional. Rio de Janeiro, v. 9, n. 1, jan-jun, p. 99-121, 2018.

GARCIA, Maria. Políticas públicas e normas programáticas: a efetividade da Constituição, a Administração Pública e o Estado de Direito. In: GARCIA, Maria (Coord.). Revista de Direito Constitucional e Internacional. São Paulo, v. 19, nº. 76, jul-set, p. 101-112, 2011.

GENTIL, Denise Lobato et al. Uma análise não convencional para o financiamento da Previdência Social no Brasil: aspectos teóricos e evidências empíricas. In: PUTY, Cláudio Alberto Castelo Branco; GENTIL, Denise Lobato (Org.). A Previdência Social em 2060: As inconsistências do modelo de projeção atuarial do governo brasileiro. Brasília: ANFIP/DIEESE, 2017.

GIMENEZ, Denis Maracci. Democracia e a Previdência Social no Brasil. Carta Social e do Trabalho, Campinas, n. 33, jan./jun., p. 59-68, 2016.

GUIMARÃES, Ulisses. Discurso na sessão de encerramento dos trabalhos da Assembleia Nacional Constituinte. Brasília, 5 out. 1988. Disponível em: https://www2.camara.leg.br/atividade-legislativa/plenario/discursos/escrevendohistoria/25-anos-da-constituicao-de-1988/constituinte-19871988/pdf/Ulysses\%20Guimaraes\%20-\%20DISCURSO\%20\%20REVISADO.pdf.

HARADA, Kiyoshi. Direito Financeiro e Tributário. 25. ed. São Paulo: Atlas, 2016.

IBRAHIM, Fábio Zambitte. Curso de Direito Previdenciário, 16. ed. Niterói: Impetus, 2011.

MACHADO, Hugo de Brito. Curso de Direito Tributário. 37. ed. São Paulo: Malheiros, 2016.

GOMES, Cláudia Maria Costa e ROJAS, Gonzalo Adrián. Crise orgânica, governos e seus impactos na América Latina. Em Pauta - Revista da Faculdade de Serviço Social da Universidade do Estado do Rio de Janeiro, Rio de Janeiro, n. 39, v. 15, 10 Semestre, p. 17-32, 2017.

MARMELSTEIN, George. Curso de Direito Fundamentais. 2. ed. São Paulo: Atlas, 2014.

MARTINS, Sérgio Pinto. Direito da Seguridade Social. 36. ed. São Paulo: Saraiva, 2016.

NABAIS, José Casalta. A face oculta dos direitos fundamentais: os deveres e os custos dos direitos. Revista Direito Mackenzie, São Paulo, v. 3, n. 2, p. 9-30, 2002.

NABAIS, José Casalta. $\mathbf{O}$ dever fundamental de pagar impostos: contributo para a compreensão do estado fiscal contemporâneo. Coimbra: Livraria Almedina, 2009.

PAULSEN, Leandro. Direito Tributário - Constituição e Código Tributário à luz da doutrina e da jurisprudência. 15. ed. Porto Alegre: Livraria do Advogado, 2013.

PENNAFORTE, Charles. De Chávez a Maduro: a Venezuela sob ataque contra antissistêmico?. Revista Intellector, Rio de Janeiro, v. XI, ano 21, jul-dez, p. 42-68, 2014. 
PIKETTY, Thomas. O capital no século XXI. Ed digital. Rio de Janeiro: Intrínseca, 2014.

SALVADOR, Evilasio da Silva. O desmonte do financiamento da seguridade social em contexto de ajuste fiscal. Serviço Social \& Sociedade, São Paulo, n. 130, set-dez, p. 426-446, 2017. Disponível em: http://dx.doi.org/10.1590/0101-6628.117.

SARLET, Ingo Wolfgang. Dignidade da Pessoa Humana e Direitos Fundamentais na Constituição Federal de 1988. 6. ed. Porto Alegre: Livraria do Advogado, 2008.

SARLET, Ingo Wolfgang. Comentário ao artigo 60. In: CANOTILHO, J. J. Gomes; MENDES, Gilmar F; SARLET, Ingo W.; STRECK, Lenio L. (Coords.). Comentários à Constituição do Brasil. São Paulo: Saraiva/Almedina, p. 1213-1226, 2018. E-book.

SARLET, Ingo Wolfgang. O Estado Social de Direito, a proibição de retrocesso e a garantia fundamental da propriedade. Revista Diálogo Jurídico, Salvador, ano I, v. I, no 4, jul., p. 1-22, 2001. Disponível em: http://livros-e-revistas.vlex.com.br/vid/retrocesso-fundamental-propriedade-59632193.

SEN, Amartya. Desenvolvimento como liberdade. 1. ed. 5. reimpressão. São Paulo: Companhia de bolso, 2016.

OLIVEIRA, Thiago e FERRAZ, Alexandre. Programa Seguro-desemprego: qual a reforma necessária? Revista Política Social e Desenvolvimento, [s.l.], p. 28-37 dez. 2015. As demandas sociais da democracia não cabem no orçamento? Parte II. Disponível em: https://revistapoliticasociale desenvolvimento.com/2015/12/24/a-democracia-nao-cabe-no-orcamento-parte-ii/.

STRECK, Lênio Luiz; MORAIS, José Luiz Bolzan de. Ciência política e teoria do estado. 3. ed. Porto Alegre: Livraria do Advogado,2003.

SUNSTEIN, Cass. The cost of rigths - Why liberty depends on taxes. New York: Norton, 1999.

TAVARES, Marcelo Leonardo e SOUSA, Ricardo José Leite. O Princípio Da Solidariedade Aplicado À Previdência Social. Revista Jurídica (0103-3506), [s. I.], v. 1, n. 42, p. 277-293, 2016. Disponível em: http://search.ebscohost.com/login.aspx?direct=true\&db=foh\&A $\quad \mathrm{N}=113852823 \&$ lang=pt-br\&site =eds-live.

TIMM, Luciano Benetti. Qual a maneira mais eficiente de prover direitos fundamentais: uma perspectiva de direito e economia?. In: SARLET, Ingo Wolfgang; TIMM, Luciano Benetti (Org.) Direitos Fundamentais - orçamento e "reserva do possível". Porto Alegre: Livraria do Advogado, 2008.

TORRES, Ricardo Lobo. Curso de Direito Financeiro e Tributário. 18. ed. Rio de Janeiro: Renovar, 2011.

TORRES, Ricardo Lobo. Comentário ao artigo 165. In: CANOTILHO, J. J. Gomes; MENDES, Gilmar F.; SARLET, Ingo W.; STRECK, Lenio L. (Coords.). Comentários à Constituição do Brasil. São Paulo: Saraiva/Almedina, 2013. E-book.

TSUTIYA, Augusto Massayuki. Curso de Direito da Seguridade Social. 4. ed. São Paulo: Saraiva, 2013. 